\title{
Too big, too small, or just right
}

\author{
Felix G. Fernandez, MD, MSc
}

\footnotetext{
From the Division of Cardiothoracic Surgery, Department of Surgery, Emory University School of Medicine, Atlanta, Ga.

Disclosures: Author has nothing to disclose with regard to commercial support.

Received for publication Nov 27, 2015; accepted for publication Nov 30, 2015; available ahead of print Jan 15, 2016.

Address for reprints: Felix G. Fernandez, MD, MSc, Division of Cardiothoracic Surgery, Department of Surgery, Emory University School of Medicine, 1365 Clifton Rd NE, Suite A2214, Atlanta, GA 30322 (E-mail: felix. fernandez@emoryhealthcare.org).

J Thorac Cardiovasc Surg 2016;151:1170

$0022-5223 / \$ 36.00$

Copyright $(c) 2016$ by The American Association for Thoracic Surgery

http://dx.doi.org/10.1016/j.jtcvs.2015.11.066
}

Currently, size matching for lung transplantation is most commonly based on comparisons of donor and recipient height in conjunction with clinical judgment guided by examination of donor and recipient radiographs. Height has been demonstrated to be a poor predictor of lung volume, however, and significant size mismatch can result in morbidity for the lung transplant recipient..$^{1}$ In this edition of The Journal of Thoracic and Cardiovascular Surgery, Konheim and colleagues ${ }^{2}$ propose the use of predictive equations for donor lung volumes to facilitate size matching in the lung transplant setting. In a retrospective cohort of 400 healthy patients, Konheim and colleagues ${ }^{2}$ rigorously trained and validated a predictive model for donor lung volumes that used lung volumes derived from 3-dimensional computed tomography (3D-CT) as the reference standard. Age, sex, height, and race were identified as predictors in this model. Although 3D-CT scans are highly accurate for measuring lung volumes, they are not commonly obtained in potential lung donors because of cost, resource allocation, and timing constraints. The routine implementation of 3D-CT for estimating donor lung volume is not likely in the future. Konheim and colleagues ${ }^{2}$ are therefore to be congratulated for devising a methodology to predict donor lung volumes on the basis of readily available patient demographic data. These equations can be implemented into clinical practice immediately as a tool to help guide selection of donor lungs, used in conjunction with available clinical data. Such work is of tremendous value in an era in which we must carefully allocate our limited health care resources.

Being able to predict donor lung volume with relatively good accuracy does not, however, completely solve the lung transplant size matching conundrum. The estimation of recipient lung volume remains problematic. For optimal size matching to occur, both donor and recipient lung volumes must be known. Patients with restrictive or obstructive pulmonary disease may not be able to generate a maximal inspiratory effort for accurate assessment of lung volumes with 3D-CT. In addition, traditional estimation of total lung capacity in the pulmonary laboratory is a measure of lung function (alveolar space) rather than an anatomic measurement. Such measurements of

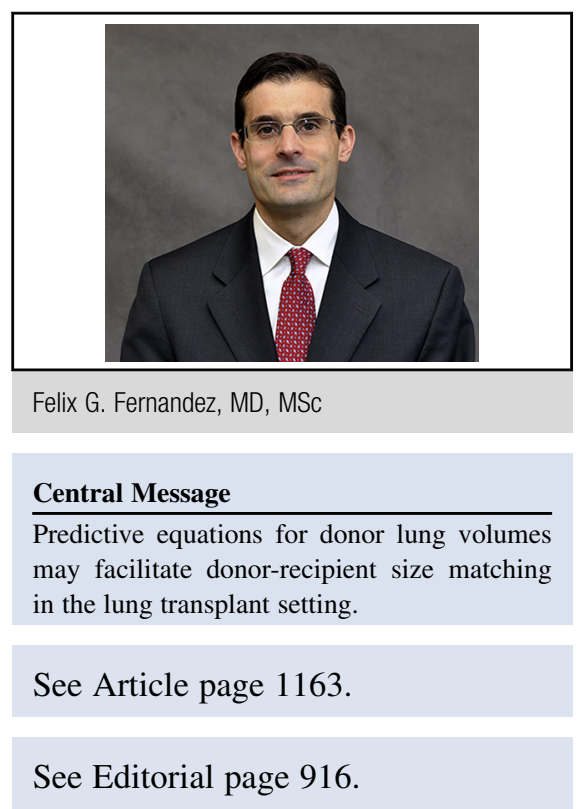

total lung capacity are likely to underestimate lung volumes in many patients with pulmonary pathology. Further, estimated lung volumes in patients with restrictive or obstructive lung disease are likely not reflective of the optimal lung volumes for these patients in the native state. Deriving the optimal recipient lung volume is more difficult.

As our ability to predict donor and recipient lung volumes continues to improve, we will undoubtedly be able to size match donor lungs more accurately with the appropriate recipient. A perfect size matching strategy, however, could lead to a restrictive approach in which patients are denied donor lungs that could still provide them substantial benefit. Future studies should aim to delineate the degree of variance that is acceptable in the size matching of donor and recipient lungs to optimize use of donor organs and clinical outcomes. Our present understanding is that is it preferable to oversize rather than undersize donor lungs. ${ }^{3}$ This study by Konheim and colleagues ${ }^{2}$ represents a positive step toward the goal of accurately determining which donor lungs are too big, too small, or just right.

\section{References}

1. Ouwens JP, van der Mark TW, van der Bij W, Geertsma A, de Boer WJ, Koëter GH. Size matching in lung transplantation using predicted total lung capacity. Eur Respir J. 2002;20:1419-22.

2. Konheim JA, Kon ZN, Pasrija C, Luo Q, Sanchez PG, Garcia JP, et al. Predictive equations for lung volumes from computed tomography for size matching in pulmonary transplantation. J Thorac Cardiovasc Surg. 2016;151:1163-9.

3. Eberlein M, Permutt S, Chahla MF, Bolukbas S, Nathan SD, Shlobin OA, et al. Lung size mismatch in bilateral lung transplantation is associated with allograft function and bronchiolitis obliterans syndrome. Chest. 2012;141:451-60. 